\section{The multidisciplinary team in child psychiatry}

There is excessive and unwarranted belief in the value of the multidisciplinary team in all referrals to Child Psychiatry. Its use is often unhelpful because other patients on the waiting list are left for very long periods of time without assessment or treatment. The only way forward in terms of use of resources would be for each referral to Child Psychiatry to have a keyworker and other members invited in at a later stage if necessary. The idea of two or three qualified members of a team observing a family at the same time is in my view not the most cost effective use of resources.

Not every child with attention deficit hyperactivity disorder needs multidisciplinary input where there are serious scarce resources. It is clear here that the major therapeutic input in attention deficit hyperactivity disorder comes from psychopharmacology and not from psychotherapeutic interventions. In the MTA study "combined and medication management treatments did not differ significantly on any direct comparisons". This is hardly surprising since attention deficit hyperactivity disorder is a $60 \%-80 \%$ genetic condition. The multidisciplinary team, in a situation of finite resources, is in need of urgent reassessment.

Michael Fitzgerald,

Henry Marsh Professor of Child and Adolescent Psychiatry, Trinity College Dublin,

Dublin 2, Ireland.

References

1. The MTA Cooperative Group, (1999). A fourteen month randomised clinical trial of the treatment strategies for Attention Deficit Hyperactivity Disorder. Arch Gen Psychiatry 1999; 56: 1073-1086.

\section{Suicidal ideation among Irish adolescents: the CDI suicide question (item 9 )}

Youth suicide has become an increasing concern in Ireland in recent years. ${ }^{1}$ Equally, concern has grown here over the issue of parasuicide ${ }^{2}$ and deliberate self-harm in children. ${ }^{3}$ However little published information on suicidal ideation among Irish children is available.

O'Sullivan and Fitzgerald 4 have formerly examined this issue in Ireland via a two-stage technique using an amended screening tool, ${ }^{5}$ and the Harkavy-Asnis Suicide Survey (HASS). ${ }^{6}$ The authors noted rates of suicidal ideation among 13 and 14 year-old Irish schoolchildren of $44 \%$ at screening and $29 \%$ at home interview. Using item 9 of the Children's Depression Inventory (CDI), ${ }^{7}$ Donnelly ${ }^{8}$ details suicidal ideation among schoolchildren in Northern Ireland. Other published research presenting norms for the CDI in Ireland did not specify responses to item 9 in isolation. ${ }^{9}$

A study of depression in schoolchildren was conducted in 2002 using the CDI. Results of responses to item 9 of this measure are detailed below. To complete item 9 , children are asked to pick one of the three following sentences that best describes them over the preceding two weeks: I do not think about killing myself; I think about killing myself but would not do it; I want to kill myself.
The target population for this study were second year and pre-Leaving Certificate pupils in 23 post-primary schools in the Mid-West region (Counties Clare, Limerick and Tipperary NR). These schools were selected by a multistage stratified random sampling method, on the basis of area and school type, and constitute one-third of the total number of secondary schools in the region. All schools approached agreed to participate in this research. A total of 2,297 postprimary school students participated in this research with an average age of 16.1 years.

Responses to item 9 indicate that more than two-thirds of children $(67.8 \%, n=1452)$ endorsed the answer 'I do not think about killing myself'. A further $28.5 \%(n=611)$ of respondents endorsed the item ' 1 think about killing myself but would not do it'. However 3.6\% $(n=78)$ of respondents positively endorsed the item 'I want to kill myself'. Examining gender, $3.2 \%(n=37)$ of boys endorsed the answer 'I want to kill myself', whereas $4.2 \%(n=40)$ of girls gave the same response (non-significant difference). Further breakdown by age and gender was not feasible given the small numbers involved, however there was a non-significant trend for younger children (13-15 years) to be more likely to endorse the answer 'I want to kill myself', $(4.0 \%, n=37)$, compared to older (16-18 years) children $(3.2 \%, n=35)$.

These results are broadly in line with other unpublished research on this topic in Ireland, which noted that $31.4 \%$ of schoolchildren (6-18 years) positively endorsed the answer to item 9 on the CDI that "I think about killing myself but would not do it', while $5.0 \%$ endorsed the answer 'I want to kill myself'. ${ }^{10}$

A third of post-primary schoolchildren in this country are positively endorsing questionnaire measures of suicidal ideation. With what we know to date of our high rate of youth suicide in Ireland, this trend is apparent and identifiable in the school age population and thus could be treated more readily. The question must be asked therefore why more is not being done to combat this tragedy that strikes Irish families, communities and society so gravely.

\section{Frank Houghton, Hilary Cowley, Kevin Kelleher Department of Public Health, Mid-Western Health Board Sharon Houghton, Brothers of Charity Services, Limerick.}

\footnotetext{
References

1. Kelleher MJ. Youth Suicide Trends in the Republic of Ireland. Br J Psychiat 1998;173 196-7.

2. National Parasuicide Registry Ireland. Annual Report 2001. Cork: National Suicide Research Foundation, 2002

3. Asady MA, Cosgrove JF, MacMahon P. Deliberate self poisonings in children and adolescents - a frightening scourge. Ir Med J 2002; 95(3): 83-4

4. O'Sullivan M, Fitzgerald M. Suicidal ideation and acts of self-harm among Dublin school children. J Adolescence 1998; 21(427): 433.

5. Meehan PJ, Lamb JA, Saltzman LE. Attempted suicide among young adults: Progress towards a meaningful estimate of prevalence. Am J Psychiat 1992; 149: 41-44.

6. Harkavy-Friedman JM, Asnis GM. Assessment of suicidal behaviour: a new instrument. Psychiatr. Annals 1989; 19: 382-387.

7. Kovacs M. Children's Depression Inventory Manual. California: Western Psychological Services 1992.

8. Donnelly M. Depression among adolescents in Northern Ireland. Adolescence 1995; 30(118): 339-50.

9. Houghton S, O'Connell M, O'Flaherty A. The use of the Children's Depression Inventory in an Irish context. Irish J Psychol 1998; 19(2-3): 313-331.

10. Houghton S. Depressive Symptomatology in Schoolchildren and the Mediating Role of Maternal Support: A Comparative Investigation with Children who have been Sexually Abused. Doctorate in Clinical Psychology, University of Dublin, Trinity College, 1998.
} 